\title{
Loss of epithelial AR increase castration resistant stem-like prostate cancer cells and promotes cancer metastasis via TGF- $\beta 1 /$ EMT pathway
}

\author{
Qiliang Cai ${ }^{1 \#}$, Yegang Chen ${ }^{1 \#}$, Dingnrong Zhang ${ }^{1 \#}$, Jiancheng Pan ${ }^{1}$, Zunke Xie ${ }^{1}$, Shenze Ma ${ }^{2}$, \\ Chuanfeng Liu ${ }^{3}$, Jiquan Zuo ${ }^{4}$, Xiaodong Zhou ${ }^{1}$, Changyi Quan ${ }^{1}$, Zhongcheng Xin ${ }^{1,5}$, Yuanjie Niu ${ }^{1}$ \\ ${ }^{1}$ Department of Urology, the Second Hospital of Tianjin Medical University, Tianjin Institute of Urology, Tianjin 300211, China; ${ }^{2}$ Department of \\ Urology, ZiBo Central Hospital, ZiBo 255000, China; ${ }^{3}$ Department of Urology, Women \& Children's Health Care Hospital of Linyi, Linyi 276000, \\ China; ${ }^{4}$ Department of Urology, the Affiliated Hospital of Qingdao University, Qingdao 266000, China; ${ }^{5}$ Andrology Center, Peking University First \\ Hospital, Peking University, Beijing 100034, China \\ Contributions: (I) Conception and design: Q Cai, C Quan, Z Xin, Y Niu; (II) Administrative support: D Zhang, Z Xie, J Zuo, X Zhou; (III) Provision \\ of study materials or patients: Q Cai, Y Chen, D Zhang; (IV) Collection and assembly of data: Q Cai, D Zhang, S Ma, C Liu; (V) Data analysis and \\ interpretation: Q Cai, Y Chen, D Zhang, J Pan; (VI) Manuscript writing: All authors; (VII) Final approval of manuscript: All authors. \\ \#These authors contributed equally to this work. \\ Correspondence to: Prof. Changyi Quan; Prof. Zhongcheng Xin; Prof. Yuanjie Niu. Department of Urology, the Second Hospital of Tianjin Medical \\ University, Tianjin Institute of Urology, Tianjin, 300211,China. Email: quancy98@hotmail.com; xinzc@bjmu.edu.cn; qlcwwtg@gmail.com.
}

Background: Previous study has reported that loss of epithelial androgen receptor (AR) may promote tumor progression and cause TRAMP mouse model die earlier. The detail mechanisms, however, remain unclear.

Methods: Immunohistochemistry assay, Western blot and real-time PCR were used to detect the expression of epithelial and mesenchymal markers. RNA extraction, RT-PCR, quantitative RT-PCR, BrdU incorporation assays, flow cytometry and other experimental technics were also used in present work.

Results: Decreased expression of epithelial markers (Cytokeratin 8, NKX3.1 and E-cadherin) and increased expression of mesenchymal markers ( $\alpha$-SMA, Vimentin, and N-cadherin) in were found in AR knockout TRAMP tumors. Further investigation indicated that AR signal deprivation is associated with cell morphology transition, high cell mobility, high cell invasion rate and resistance to anoikis in TRAMP prostate tumor cells. Together, these findings implied knockout AR in TRAMP prostate tumor may lead to EMT, which may result in earlier metastasis, and then cause TRAMP mice die earlier. TGF- $\beta 1$ is responsible for EMT in AR knockout TRAMP tumor cells.

Conclusions: In conclusion, ADT therapy induced hormone refractory prostate cancer may gain the ability of metastasis through cell's EMT which is a phase of poor differentiation. Anti-EMT drugs should be developed to battle the tumor metastasis induced by ADT therapy.

Keywords: Prostate cancer; androgen receptor; TGF- $\beta$; EMT; metastasis

Submitted Feb 06, 2020. Accepted for publication Mar 13, 2020.

doi: $10.21037 /$ tau.2020.03.02

View this article at: http://dx.doi.org/10.21037/tau.2020.03.02 


\section{Introduction}

Prostate cancer (PCa) is the second leading causes for cancer mortality of men in USA and the most commonly confirmed non-skin cancer, worldwide (1). Failure to cure patients with tumor metastasis is the most primary reason for death from prostate cancer. In PCa early period, androgens were responsible for tumor development. Therefore, androgen deprivation therapy (ADT) can be implemented to suppress tumor growth (2). However, the final recurrence of $\mathrm{PCa}$ is on account of the androgen independence tumor, one of the reasons for tumor high metastasis, replacing the initial most composition of androgen dependence tumor. Currently, there is no effective treatment for cancer metastasis.

For the development and growth of prostate, interactions between androgens and epithelial-mesenchymal is indispensable. Within the prostate glands epithelium and stroma, androgen receptor (AR)-associated androgen signaling pathway is observed $(3,4)$. An absence of functional AR/androgen signaling mice lead to abnormal prostate $(5,6)$. Groundbreaking research on prostate development exhibited that apoptosis, bud formation, epithelial cell identify, proliferation, and ductal branching are identified by specification of stroma AR, not epithelium $(7,8)$. Epithelium AR, however, promotes cell proliferation stimulated by androgen, which has been observed and evidenced by many anaplastic PCa cells research (9-11). ADT has become the key therapy of tumor metastasis or advanced PCa based on this notion and premise.

Our previous study has showed that the AR functions were different in different prostate cells, such as: as tumor inhibitor to depress tumor metastasis in epithelial basal intermediate cells, as survival factor and expansion factor to advance the tumor survival and development. Meantime, it also can cause loss of epithelial AR mice die earlier $(12,13)$. The detail mechanisms, however, remain unclear.

Mesenchymal cells characteristics replaced lots of epithelial cells initial properties in epithelial cells for the reason of Epithelial-mesenchymal transition (EMT) (14). Therefore, it is a key role in order to ascertain tumor cells spread (15). According to current study, it has been observed that EMT-related signaling pathways were negative correlation for AR density (16). Therefore, EMT may be easily occur when AR axis are disrupted during tumor progression.

Using the pes-ARKO-TRAMP Mice, it was observed that knockdown-AR could induce EMT of the pesARKO-TRAMP Mice tumor cells. This outcome beyond expectation may explain the reason of failure of androgen deprivation therapy in almost long-term treatment patients. Moreover, it also can provide an urgent need to develop new approaches that gives castration therapy at earlier stages and prevents EMT to treat prostate cancer.

\section{Methods}

\section{Cell culture and reagents}

The LNCaP human early androgen-dependent prostate cancer cell line and CWR22rv1 (CRL-2505) castration resistant prostate cancer cell line were purchased from the China Type Culture Collection, cultured in recommended medium with supplement of $10 \%$ fetal bovine serum (FBS; Gibco, California, USA) and incubated at $37{ }^{\circ} \mathrm{C}$ within humidified atmosphere including $5 \% \mathrm{CO}_{2}$. Meantime, $25 \mathrm{U} / \mathrm{mL}$ penicillin and $25 \mu \mathrm{g} / \mathrm{mL}$ streptomycin were added to them.

\section{Generation of pes-ARKO-TRAMP mice}

To product TRAMP-floxed female mice, mice with the conditional AR allele (floxed AR, C57BL/6) were used to mate with TRAMP mice. Then to generate pes-ARKOTRAMP male and littermates Wt-AR-TRAMP mice, ARR2PB2-Cre male mice (C57BL/6N) were used to mate with TRAMP-floxed AR female mice. TRAMP (FVB) were purchased from Jackson Laboratory and Probasin Cre (pb-Cre)(C57BL/6) mice from NCI. Using R26R/ $\beta$-Gal transgenic female mice were mated with pes-ARKOTRAMP male mice to generate pes-ARKO-TRAMP $\beta$-Gal transgenic mice. After 12 weeks feeding, mice were killed and then fresh tissue samples were exteriorized to conduct $\beta$-Gal staining. The microscopy was used to identify the $\beta-$ Gal-positive cells.

\section{Tumor orthotopic transplantation in nude mice}

8 -wk nude mice without thymus were selected to orthotopically implant CWR22rv1-AR+/+ cells and CWR22rv1-AR+/- cells in their prostate anterior lobe by opening abdomen under anesthesia and sterile condition. We choose 25-gauge needle to inject the CWR22rv1$\mathrm{AR}+/+$ cells and CWR22rv1-AR+/- cells into one anterior lobe. The cells were calculated and suspended in $50 \mu \mathrm{L}$ Matrigel with $10^{6}$ cells $/ \mu \mathrm{L}$, and then sutured the abdomens. 12 weeks later, we killed the mice, incised the xenograft and 
metastatic tumors, followed by fixing and embedding the samples in paraffin for future research.

\section{RNA extraction, RT-PCR, and quantitative RT-PCR}

TRIzol reagent (Invitrogen) was used to extract total RNA from tissues and cells, under manufacturer's instructions. Each isolated RNA sample $(5 \mu \mathrm{g})$ was reverse-transcribed into cDNA $(20 \mu \mathrm{L})$ using a miScript II RT Kit (Invitrogen) according to the manufacturer's instruction. After diluting the cDNA 10 times with water, we took out $2 \mu \mathrm{L}$ cDNA for PCR amplification template ABI 7500 System (Applied Biosy stems, USA) was applied to carry out the RT-PCR reactions. Beacon Designer 2 software were used to design primers. The $\beta$-actin was as control in each PCR reaction. According to the $\beta$-actin calculated threshold (CT) values levels, we deduced the samples CT values. Agarosegel electrophoresis informed the absence of nonspecific amplification products. All the assays' procedures repeat in triple.

\section{Immunobistochemistry staining}

We sliced the paraffin-embedded samples and stained the slice. The anti-CK8 (Abcam), anti-CK5 (Covance), the rabbit anti-AR (C19) (Santa Cruz Biotechnology), rabbit anti-Tag (Santa Cruz), rabbit anti-Tag (Santa Cruz) was employed as primary antibodies. Afterwards, the biotinylated secondary antibody was used to recognize primary antibody followed by using peroxidase substrate DAB kit (Vector) to visual. Image J software approximately quantified positive signals strength.

\section{BrdU incorporation assays}

We fabricated Bromodeoxyuridine (BrdU) (sigma) solution (10 mg/mL). Beginning with $24 \mathrm{~h}$ before sacrifice, mice were injected BrdU solution $(10 \mu \mathrm{g} / \mathrm{g})$ by intraperitoneal injection every $6 \mathrm{~h}$. After incising, fixing and embedding the tumors in paraffin, we marked samples by using BrdU Staining Kit (Zymed) according to recommend protocol.

\section{Obtain selected prostate cells by Laser-Capture microdissection}

Samples were stored in O.C.T. placing in $-80{ }^{\circ} \mathrm{C}$ condition as standby. For separating the epithelium and stroma cells, we first cut 5-m specimens sections, placed them on slides.
Subsequently, HistoGene LCM Frozen Section Staining Kit (Arcturus) was immediately used to stain the specimens' sections according to manufacturer's recommend. Prostatic epithelium and stroma cells were separated into different capes by laser transferring under the Pixcell II LCM system. PicoPure RNA Isolation Kit (Arcturus), a kind of RNA extraction buffer, was used to merge capes and extract RNA according to instruction after microdissecting. Then, we amplified and reverse transcribed the RNA, and analyzed genes' changes by qRT-PCR.

\section{Flow cytometry}

Trypsin-EDTA were used to digest the cells, separate cells $\left(1 \times 10^{6}\right)$ for each other, and then cells were fixed by $70 \%$ ethanol at $4{ }^{\circ} \mathrm{C}$ condition. $12 \mathrm{~h}$ later, we centrifuged the cells treated before during $7 \mathrm{~min}$ by $1,000 \times \mathrm{g}$ at $4{ }^{\circ} \mathrm{C}$ condition, suspended cells in PBS with $0.05 \mathrm{mg} / \mathrm{mL}$ Rnase A(Sigma), afterwards incubated cells during $30 \mathrm{~min}$ at room temperature. $30 \mathrm{~min}$ later, propidium iodide $(10 \mathrm{mg} / \mathrm{mL})$ were performed to stain the cells. Then we used flow cytometry (FACSCalibur, BD Company) to analyzed 10,000 cells and the result were analyzed by ModFit software (Verity Software House, Inc.).

\section{Statistics}

We showed the data in the mean + standard deviation (SD). Two-sided Student's t test was used to compare two groups and Kaplan-Meier analysis and log-rank tests were performed to analyze Survival curves.

\section{Results}

\section{AR loss led to the expression changes of EMT markers}

We found ARKO prostate tumors lost more cytokeratin markers than the AR Wt prostate tumors. From 16 to 24 wks, all prostate tumors gradually lost CK8 expression. Although pes-ARKO-TRAMP prostate tumors contains more basal intermediate cell population in $16 \mathrm{wks}$ than Wt TRAMP tumor in the same age, ARKO tumors finally decreased both CK5 and CK8 staining in the later tumor stage (Figure 1A). Immunohistochemical staining showed tumors from pes-ARKO-TRAMP prostate expressed less E-cadherin than tumors from Wt-TRAMP in $16 \mathrm{wks}$, 20 and $24 \mathrm{wks}$ (Figure $1 B$ ). But in the $24 \mathrm{wks}$ prostate tumors, pes-ARKO-TRAMP tumors expressed higher 


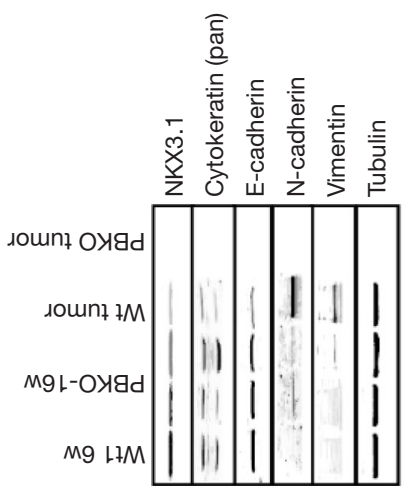

ш

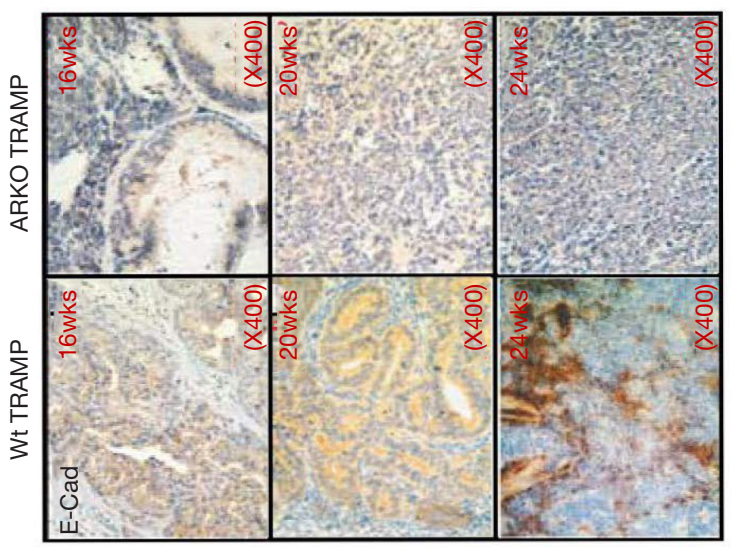

$\infty$

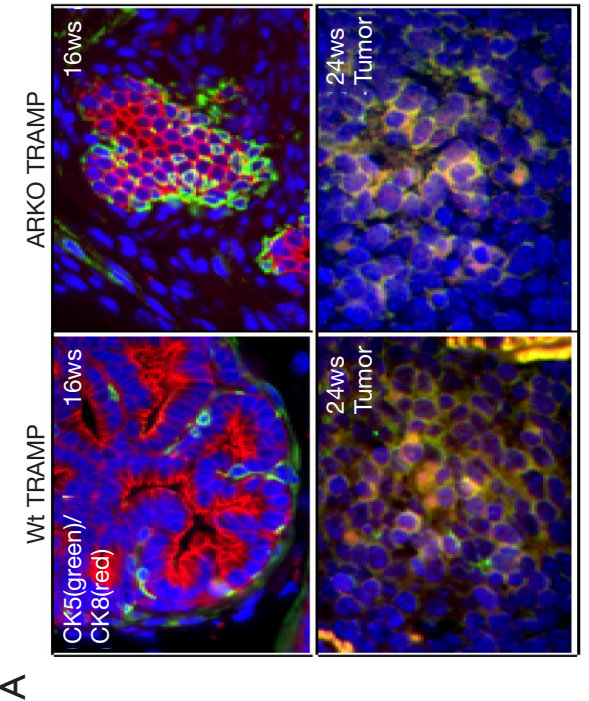

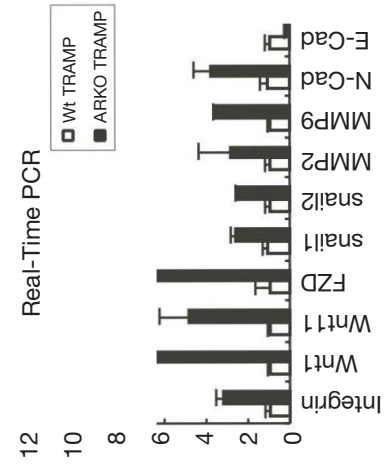

s|әлә| ио!ssəגdxə әм!ฺщ|әу

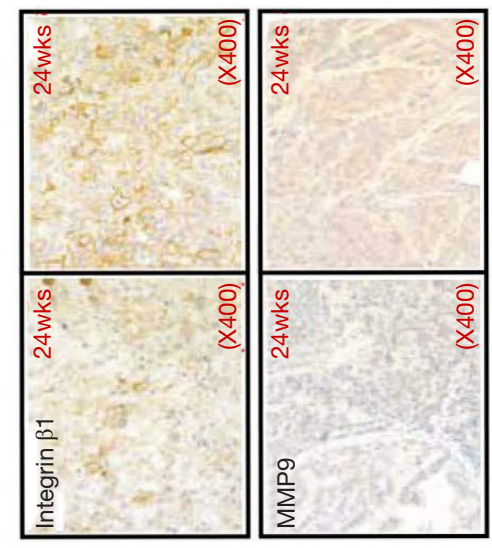

○
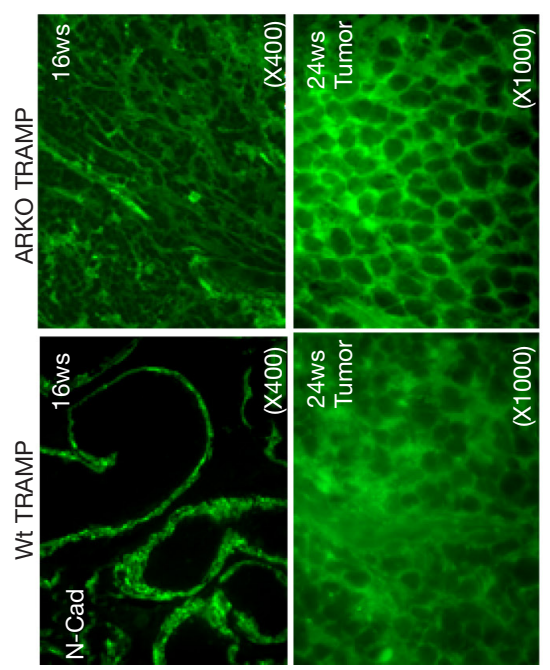

$\cup$

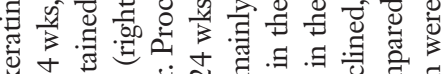

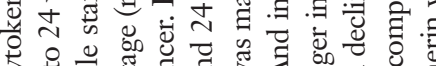

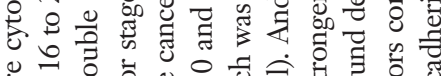

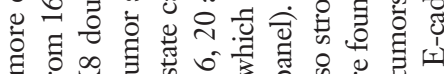

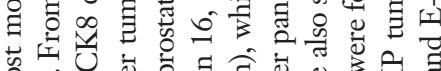

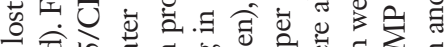

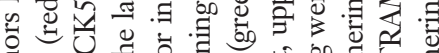

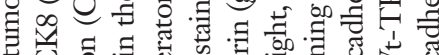

U

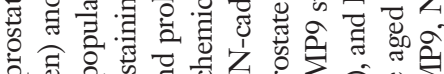

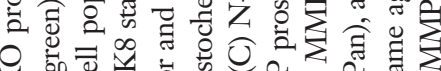

$\checkmark$ t⿹丁口

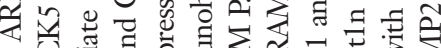

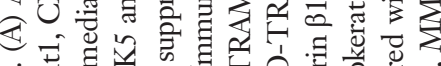

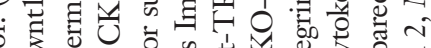

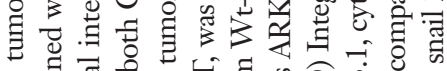

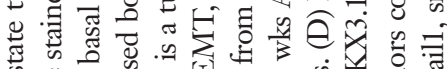

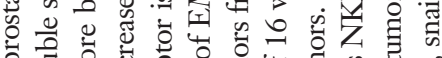

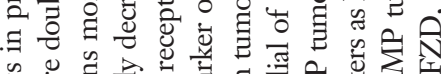

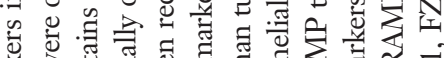

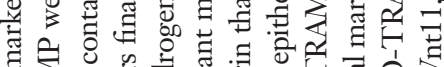

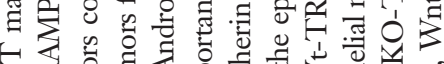

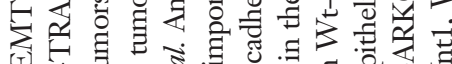

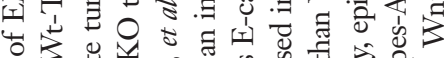

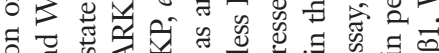

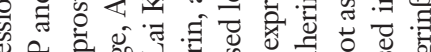

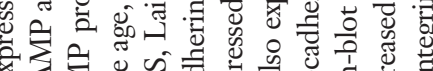

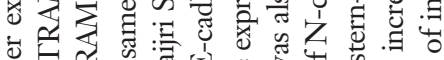

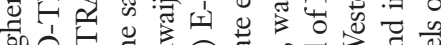

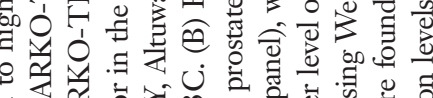

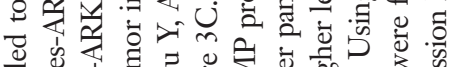

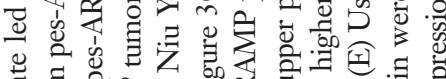

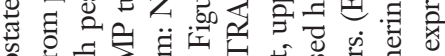

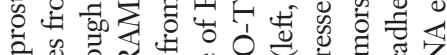

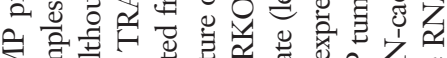

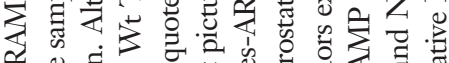

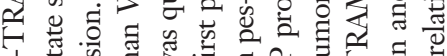

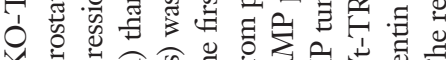

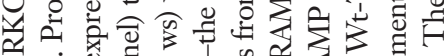

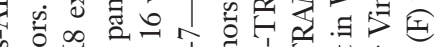

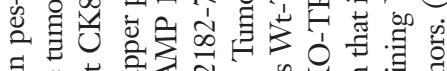

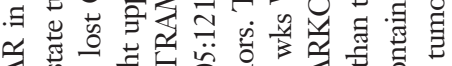

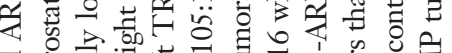

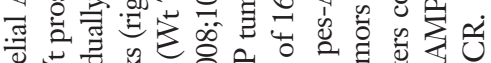

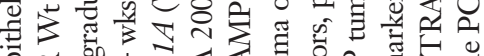

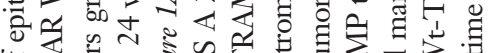

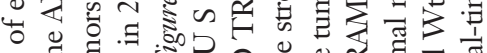

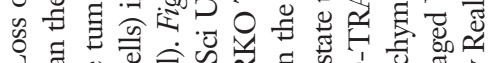

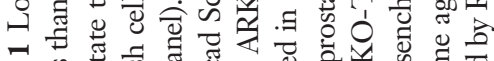
v

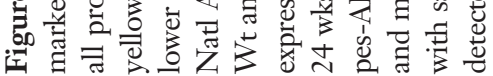


levels of N-cadherin than Wt TRAMP tumors (Figure 1C). Integrin $\beta 1$ and MMP9 staining were also stronger in the pes-ARKO-TRAMP tumors than that in Wt TRAMP tumors (Figure 1D); Using Western-blot assay, epithelial markers as NKX3.1, cytokeratin (Pan), and E-cadherin were found decline, and mesenchymal markers including Vimentin and $\mathrm{N}$-cadherin were found increase in pesARKO-TRAMP tumors compared with same aged $\mathrm{Wt}$ TRAMP tumors (Figure 1E). The relative RNA expression levels of integrin $\beta 1, W n t 1, W n t 11, F Z D$, snail1, snail2, MMP2, MMP9, N-cadherin and E-cadherin were identical with Western-blot assay results (Figure $1 F$ ). These results indicate that high expression of mesenchymal markers appeared in pes-ARKO-TRAMP prostate when epithelial AR lost.

\section{AR loss increased EMT phenotypes in term of cell morphology, detachment, motility and invasion}

We subsequently found that after $48 \mathrm{hrs}$ of cell culture, the primary cells from ARKO-TRAMP prostate tumor were clustered with elongated, spindle-like cells, while the primary cells from $\mathrm{Wt}$-TRAMP prostate tumor were scattered with round and polygonal-like cells (Figure $2 A$ ). Meanwhile, the cell invasion rate was higher in the primary cultured ARKO cells than that in Wt cells (Figure 2B). We confirmed that cell invasion was significantly increased in AR knockdown CWR22rv1 (marked as CWR22rv1$\mathrm{AR+} /-)$ cells comparing with their parental cells (marked as CWR22rv1-AR+/+) (Figure 2C). We also detected Cell motility in a wound healing assay, both CWR22rv1$\mathrm{AR}+/-$ and CWR22rv1-AR+/+ cells were grown to nearly confluency, and monolayers were scratched with a pipette tip. Cell motility was photographed $24 \mathrm{hr}$ after wound scratch. We found that the migration of the AR knockdown CWR22rv1-AR+/- cells was higher than CWR22rv1$\mathrm{AR}+/+$ cells, and $10 \mathrm{nM}$ DHT suppressed the migration of both cells (Figure 2D). And CWR22rv1-AR+/- cells were easier to be detached by EDTA than CWR22rv1$\mathrm{AR}+/+$ cells, and $10 \mathrm{nM}$ DHT suppressed the detachment of both cells (Figure 2E). $10 \mathrm{nM}$ DHT protected LnCaP cells from detachment treated by EDTA (Figure $2 F$ ). Our data confirmed that loss of AR increase EMT phenotypes in term of cell morphology, detachment, motility and invasion.

\section{AR loss resulted in fewer anoikis cells}

A Poly-Hema coated plate or a tissue culture control plate was performed to seed both CWR22rv1-AR+/+ and CWR22rv1-AR+/- cells (50,000 cells/well). Culturing cells for 24 hours, then we determined cell activity by Calcein $\mathrm{AM}$ (green), while stained death anoikis-like cell by EthD1 (red) (Figure 3A,B). The anoikis cells were counted by flowcytometry and were subsequently quantitated shown in (Figure 3C,D) $\mathrm{LNCaP}$ cells with or without $10 \mathrm{nM}$ DHT treatment were also submitted to detect the anoikis by flowcytometry. The quantitative data was shown in (Figure 3E). These data were shown that decreased expression and function of AR in CWR22rv1 cells and $\mathrm{LNCaP}$ cells resulted in fewer anoikis cells.

\section{AR loss developed larger xenograft tumors and early lymph nodes metastasis}

Both CWR22rv1-AR+/- cells and CWR22rv1-AR+/+ were orthotopically transplanted into the prostate anterior lobe of nude mice. 12 wks following implantation, mice were sacrificed, and tumors and lymph nodes were harvested (Figure $4 A$ ). The xenograft primary tumors in the prostates were weighted (Figure $4 B$ ) and the weight of the metastatic lymph nodes was also scaled (Figure 4C). We found that AR knockdown tumors from CWR22rv1-AR+/- xenografts and lymph nodes expressed less E-cadherin than that of CWR22rv1-AR+/+ xenografts and lymph nodes (Figure 4D). Snail1 expression was higher in CWR22rv1-AR+/xenograft tumors (Figure 4E). Mesenchymal markers of $\alpha$-SMA, N-cadherin, vimentin, MMP9, and integrin- $\alpha 5$ were significantly increased in CWR22rv1-AR+/- xenograft tumors comparing with those in CWR22rv1-AR+/xenograft tumors (Figure 4F). Epithelial markers of CK8, CK5, E-cadherin, NKX3.1 and PSA, except PSP94, were significantly decreased in CWR22rv1-AR+/- xenograft tumors comparing with those in CWR22rv1-AR+/xenograft tumors (Figure $4 G$ ). Signaling difference, which may involve in EMT, was also investigated and compared (Figure 4H). These observations implicated that Snail1, $\alpha$-SMA, N-cadherin, vimentin, MMP9, and integrin- $\alpha 5$ expression increased in response to AR loss, possibly facilitated CWR22rv1-AR+/- cells tumor metastasis.

\section{AR loss induced EMT may be responsible for early cancer metastasis}

Subsequently, we found that at $20 \mathrm{wks}$, pes-ARKO-TRAMP mice developed larger tumors than the Wt-TRAMP mice. The large tumors of pes-ARKO-TRAMP mice began to 
A EMT morphology changes

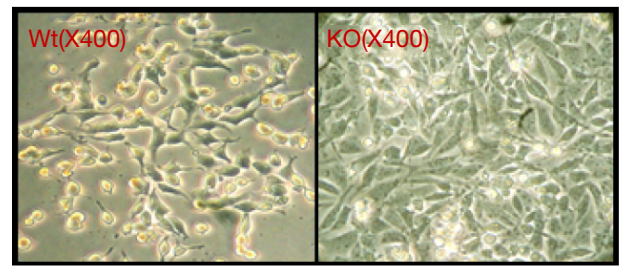

C

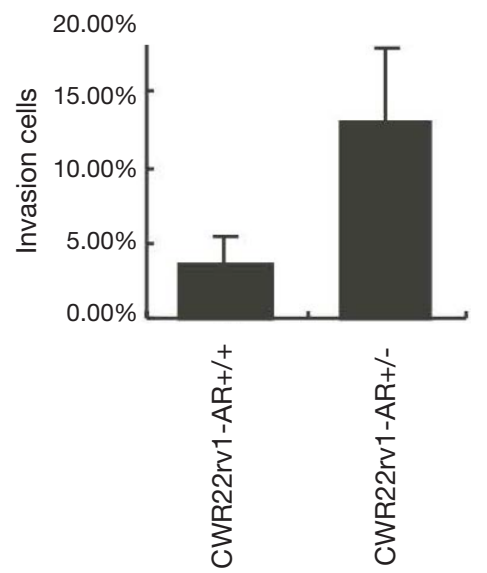

E

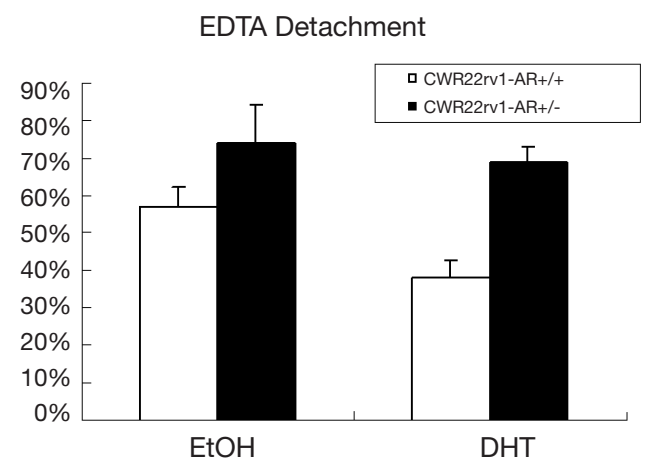

B

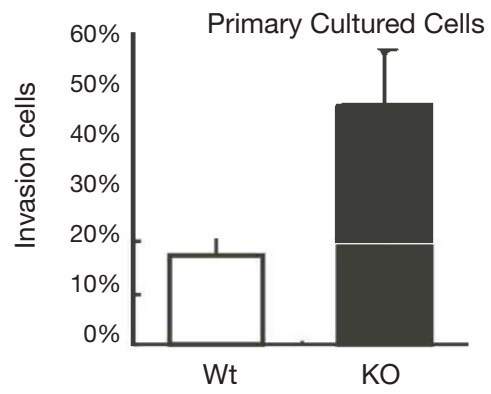

D

No DHT $10 \mathrm{nM}$ DHT

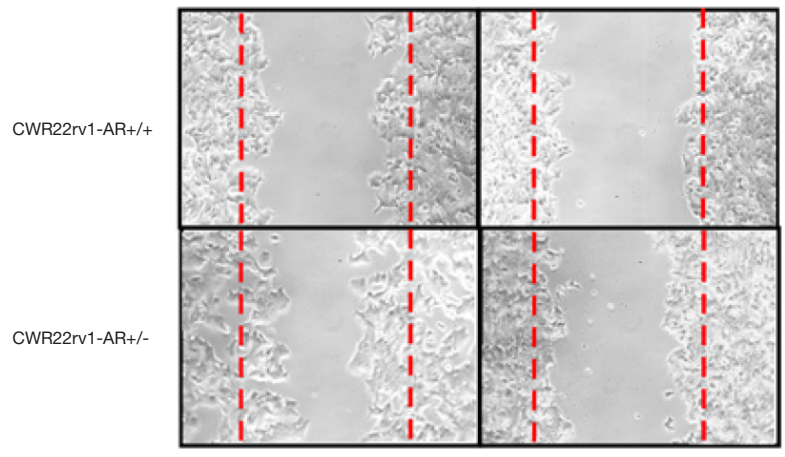

F LNCaP EDTA Detachment

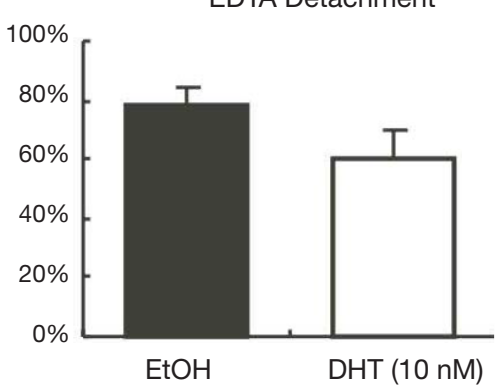

Figure 2 Loss of AR increases EMT phenotypes in term of cell morphology, detachment, motility and invasion. (A) After 48 hrs of primary culture, the primary cells from ARKO-TRAMP prostate tumor are clustered with elongated, spindle-like cells, while the primary cells from Wt-TRAMP prostate tumor are scattered with round and polygonal-like cells. (B) Meanwhile, the cell invasion rate is higher in the primary cultured ARKO cells than that in Wt cells (C) We confirmed that cell invasion was significantly increased in AR knockdown CWR22rv1 (marked as CWR22rv1-AR+/-) cells comparing with their parental cells (marked as CWR22rv1-AR+/+). (D) Cell motility was detected in a wound healing assay. Both CWR22rv1-AR+/- and CWR22rv1-AR+/+ cells were grown to nearly confluency, and monolayers were scratched with a pipette tip. Cell motility was photographed 24 hrs after wound scratch. The migration of the AR knockdown CWR22rv1-AR+/- cells was higher than CWR22rv1-AR+/+ cells, and $10 \mathrm{nM} \mathrm{DHT}$ suppressed the migration of both cells. (E) And CWR22rv 1-AR+/- cells were easier to be detached by EDTA than CWR22rv1-AR +/+ cells, and $10 \mathrm{nM} \mathrm{DHT}$ suppressed the detachment of both cells. (F) $10 \mathrm{nM}$ DHT protected LNCaP cells from detachment treated by EDTA. 

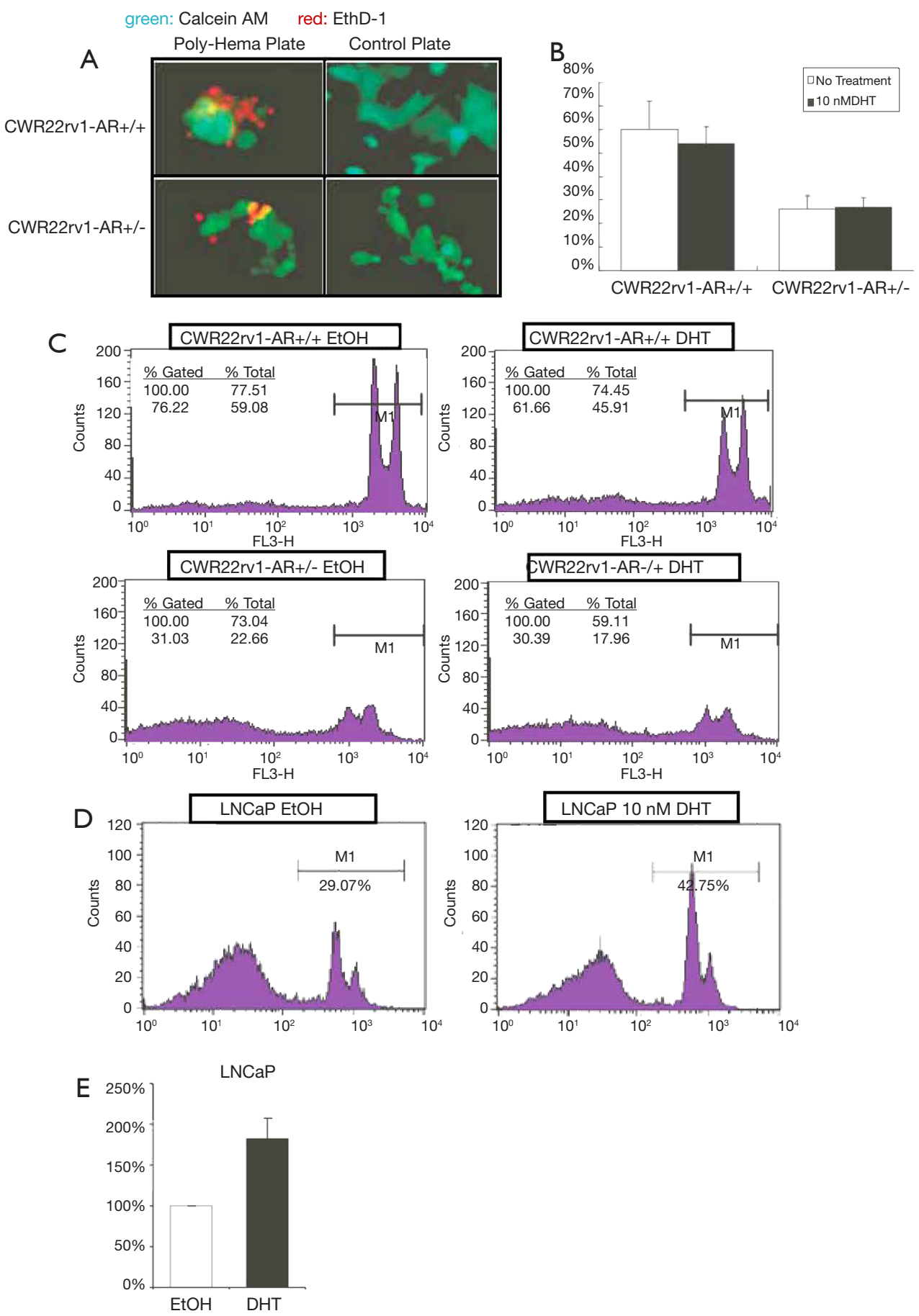

Figure 3 Decreasing the expression and function of AR in CWR 22rv1 cell and LNCaP cells resulted in fewer anoikis cells. (A) A Poly-Hema coated plate or a tissue culture control plate was performed to seed both CWR22rv1-AR+/+ and CWR22rv1-AR+/- cells (50,000 cells/well). Culturing cells for 24 hours, then we determined cell activity by Calcein AM (green), while stained death anoikis-like cell by EthD-1(red). (B) The anoik1s cells were counted by flowcytometry and were subsequently quantitated shown in (C). (D) LNCaP cells with or without $10 \mathrm{nM}$ DHT treatment were also submitted to detect the anoikis by flowcytometry. The quantitative data was shown in (E). 

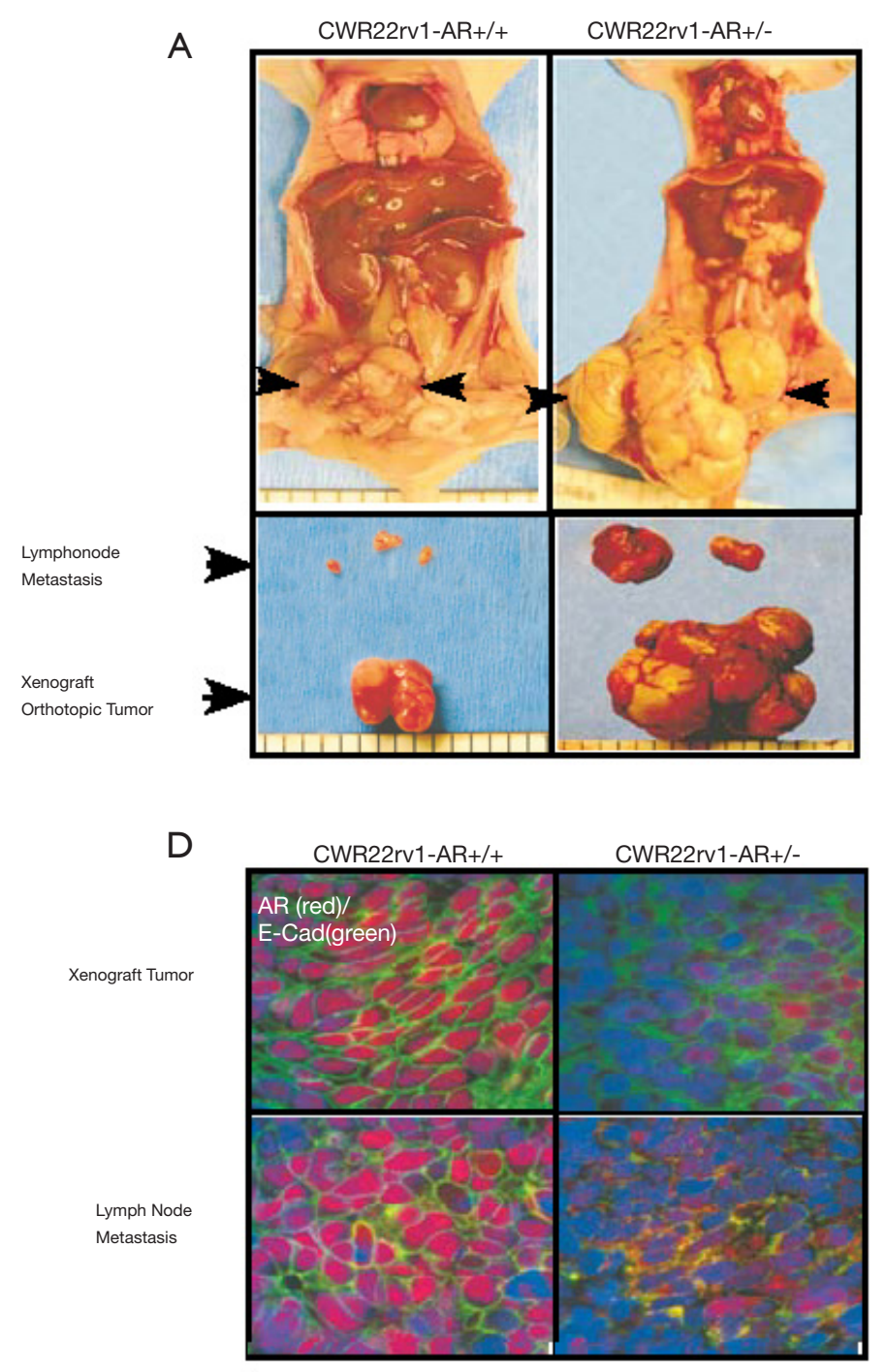

$E$

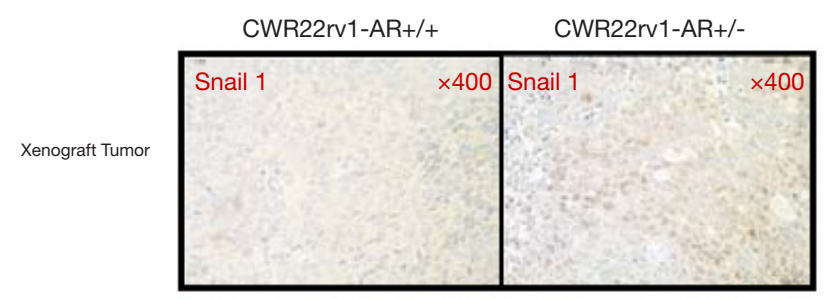

B

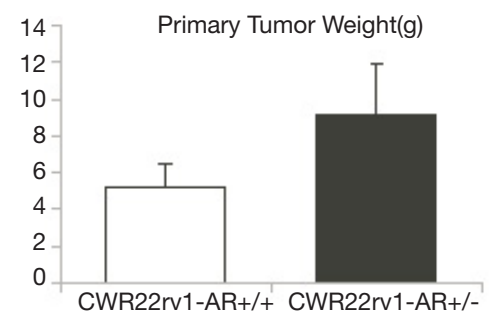

C

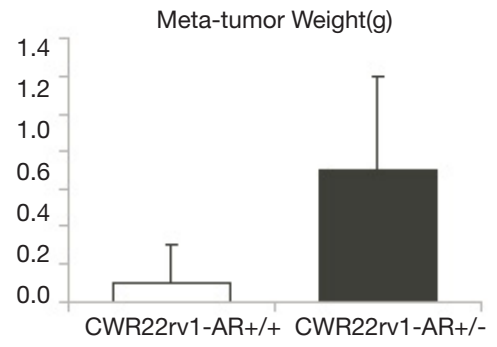

$\mathrm{F}$

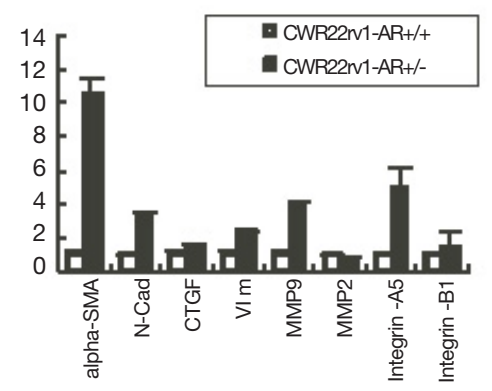

G

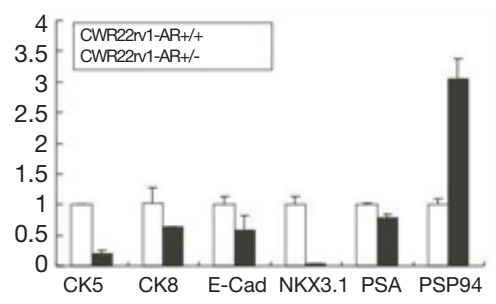

$\mathrm{H}$

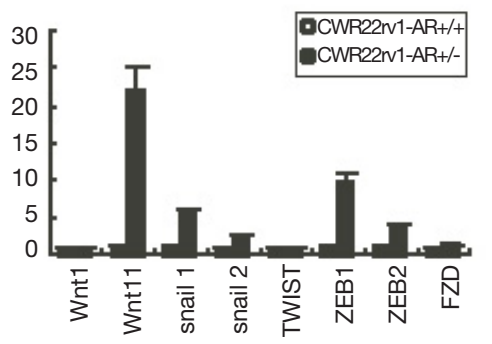

Figure 4 Androgen receptor signaling blocking may induce EMT and metastasis in vivo and in vitro. (A) Both CWR22rv1-AR+/+ cells and CWR22rv1-AR+/- cells were orthotopically implanted into the anterior lobe of nude mice. 12 wks following implantation, mice were sacrificed, and tumors and lymph nodes were harvested. (B) The xenograft primary tumors in the prostates were weighted. (C) The weight of the metastatic lymph nodes was also scaled. (D) Samples from the xenograft tumors and metastatic lymph nodes of each group were double stained by androgen receptor (red) and E-cadherin (green). AR knockdown tumors from CWR22rv1-AR+/- xenografts and lymph nodes expressed less E-cadherin than that of CWR22rv1-AR+/+ xenografts and lymph nodes. (E) Snail1 expression was higher in CWR22rv1AR+/- xenograft tumors (F) Mesenchymal markers of $\alpha$-SMA, N-cadherin, vimentin, MMP9, and integrin- $\alpha 5$ were significantly increased in CWR22rv1-AR+/- xenograft tumors comparing with those in CWR22rv1-AR +/- xenograft tumors. (G) Epithelial markers of CK5, CK8, E-cadherin, NKX3.1 and PSA, except PSP94, were significantly decreased in CWR22rv 1-AR+/- xenograft tumors comparing with those in CWR22rv1-AR+/- xenograft tumors. (H) Signaling difference, which may involve in EMT, was also investigated and compared. 
develop metastatic tumors in lymph node from $20 \mathrm{wks}$, which were larger and more lesion foci than those of $\mathrm{Wt}$ TRAMP mice (Figure $5 A$ ). The tumor samples from $20 \mathrm{wks}$ pes-ARKO-TRAMP and Wt-TRAMP prostate were double stained by T-antigen (Red) and $\mathrm{N}$-cadherin (green). $\mathrm{N}$-cadherin expression was increased in ARKO tumors (Figure $5 B$ ). The increased $\alpha$-SMA, decreased AR and CK8 expressions were detected by Real-time PCR in ARKO tumors and lymph nodes (Figure 5C). Illustrating the evolutional events in which the tumor cells keep transiting (Figure 5D). Our data showed that AR loss induced EMT transition may be responsible for the early metastasis of the pes-ARKO-TRAMP tumors again.

\section{The mechanism may involve in the AR loss triggered EMT}

In view of the widely acknowledged role of TGF- $\beta$ as a potent EMT inducer, we examined TGF- $\beta 1$ signaling. We found that of TGF- $\beta 1$, phospho-Smad $2 / 3$, phosphoAKT, phospho-JNK, phospho-GSK3 $\beta, \beta$-catenin and snail1 proteins expression increased by IHC staining and Westernblot assay in ARKO mice than that in WT mice (Figure $6 A, B)$. Furthermore, we found that TGF- $\beta 1$ signaling through phosphor-AKT to activate snail1 and to result in EMT, which is characterized by decreased E-cadherin and increased $\alpha$-SMA expression, was blocked by PI-3 K inhibitor LY294002 (Ly) (Figure 6C). Subsequently, we used Real-time PCR to test the concept that the TGF- $\beta 1$ signaling is important for the EMT transition of CWR22rv1 cells. In the left panel, without any treatment, AR knockdown CWR22rv1-AR+/- cells expressed more mesenchymal markers, such as $\alpha$-SMA, $\mathrm{N}$-cadherin, MMP9 and integrin $\beta 1$, than those of CWR22rv1-AR+/+ cells. $10 \mathrm{ng} / \mathrm{ml}$ TGF- $\beta 1$ treatment further induced the mesenchymal markers expression in CWR22rv1-AR+/cells (middle panel). By using TGF- $\beta 1$ receptor II siRNA (marked as TGF-bRIIsi), we confirmed that the expression of these mesenchymal markers was significantly reduced in CWR22rv1-AR+/- cells (right panel) (Figure 6D). In addition, the Real-time PCR results showed the TGF- $\beta 1$ signaling and blocking TGF- $\beta 1$ signaling significantly changed the expression of epithelial markers, such as CK8, E-cadherin, PSA, and Nkx3.1, in CWR22rv1-AR+/cells (Figure 6E). The Real-time PCR results showed the TGF- $\beta 1$ effects on the Wnt, snail, and ZEB signaling (Figure $6 F$ ). TGF- $\beta 1$ induced and TGF-bRIIsi suppressed CWR22rv1-AR+/- cells invasion in CWR22rv1-AR+/cells (Figure 6G). A clear consequence of the results here presented is that TGF- $\beta 1$ induced EMT sensitizes prostate tumor cells to respond to AR loss.

The relevant mechanisms are illustrated in Figure 7. Androgen-binding AR inhibits TGF- $\beta$-related Pathway. However, through binding signal molecules to TGF- $\beta$ receptors (TGF- $\beta$ R 1 and TGF- $\beta$ R2), the receptors are phosphorylated activating the SMAD signaling pathway and the non-SMAD signaling pathway. The SMAD signaling pathway begins with the co-SMAD gaining phosphorylation from TGF- $\beta$ receptor, and then binding to SMAD4 to form SMAD complex. The complexes enter the nucleus and bind the transcription factors of Snail genes promoting the expression of Snaill. Because Snail1 is the key protein of EMT, it can induce the production of EMT. Non-SMAD pathways include TAK1 signaling and PI-3k signaling pathway, etc. The TAk1 signaling pathway starts with the phosphorylation of TAK1 factors, which lead to JNK phosphorylation acting on c-JUN to regulate the transcriptional activity of cells and promote cell proliferation and inhibit cells apoptosis. And PI$3 \mathrm{~K}$ signaling pathway is caused by PI-3K factors binding phosphoric acid groups which lead to phosphorylation of AKT. Inhibition of GSk $3 \beta$ and $\beta$-catenin Phosphorylation by phospho-AKt reduces the degradation of $\beta$-catenin, and then $\beta$-catenin converging in nucleus promotes cell proliferation and inhibits apoptosis by binding transcription factors. Furthermore, phospho-AKt factors can also lead to EMT by directly promoting the expression of EMT-related key proteins.

\section{Discussion}

EMT is one mark of epithelial cancer progression. Tumor cells lose cell-cell junctions and polarity and acquire many mesenchymal characteristics, the matrix invasion making cell metastasis $(17,18)$. In this research, we have provided a lot of evidence that AR signal deprivation in TRAMP prostate tumor lead to epithelial-mesenchymal transition.

We generated pes-ARKO-TRAMP mice that spontaneously developed prostate cancers without $A R$ in cancer epithelial cells. We found that loss of epithelial AR in pes-ARKO-TRAMP mice prostate led to the epithelial markers decrease (E-cadherin, Cytokeratin 8 and NKX3.1) and mesenchymal markers increase (Vimentin, $\alpha$-SMA, and $\mathrm{N}$-cadherin). Compared with the loss of E-cadherin, $\mathrm{N}$-cadherin up-regulating expression has been previously described during the progression of various cancer types and is thought to be necessary for tumor cells to gain invasive 

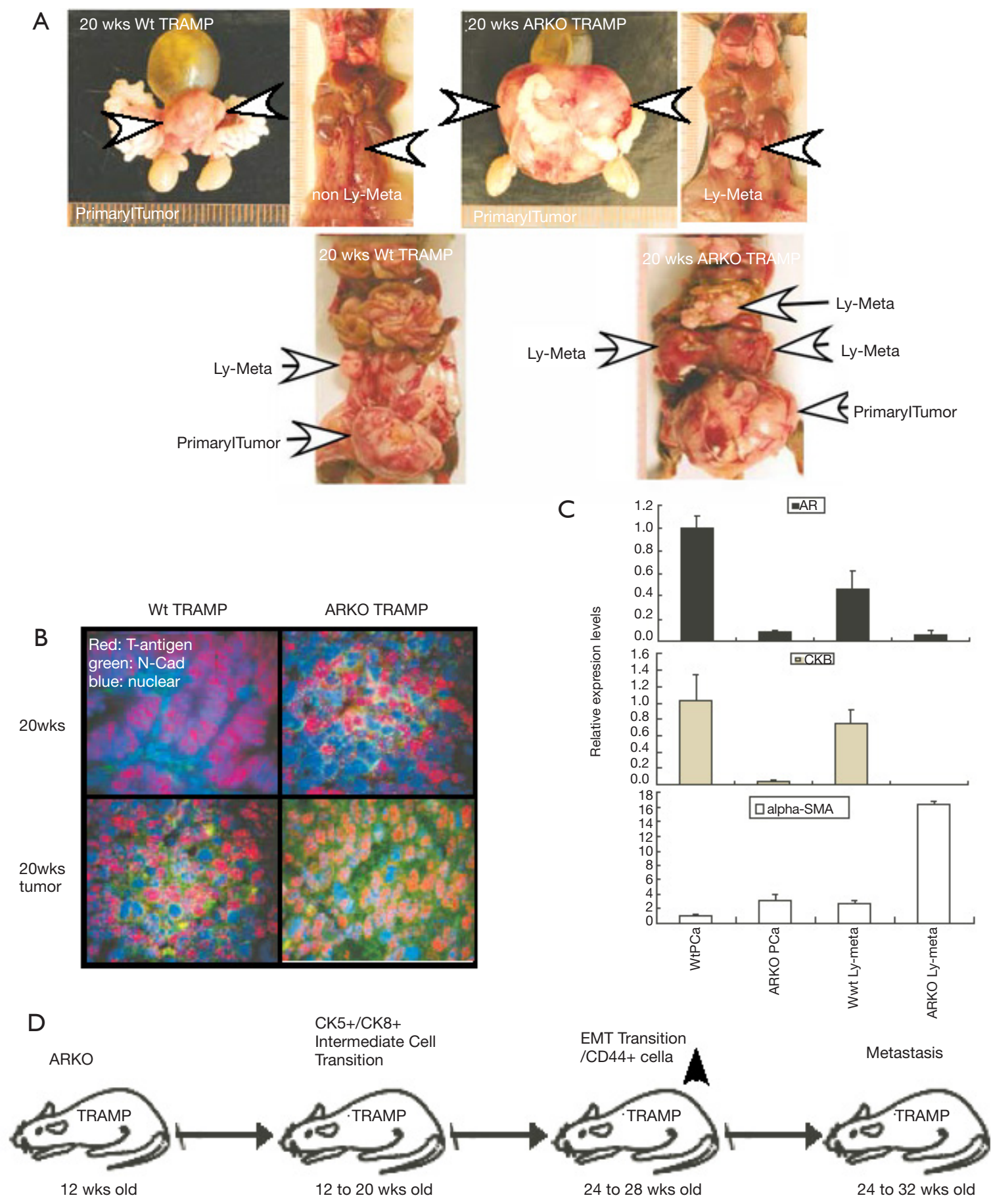

Figure 5 AR loss induced EMT transition may be responsible for the early metastasis. (A) At 20 wks, pes-ARKO-TRAMP mice developed larger tumors than the Wt-TRAMP mice. The large tumors of pes-ARKO-TRAMP mice began to develop metastatic tumors in lymph node from $20 \mathrm{wks}$, which were larger and more lesion foci than those of Wt-TRAMP mice. The last picture of Figure $5 A$ was quoted from: Niu Y, Altuwaijri S, Yeh S, et al. Targeting the stromal androgen receptor in primary prostate tumors at earlier stages. Proc Natl Acad Sci U S A 2008;105:12188-93-the second picture of Figure 5A. (B) The tumor samples from 20 wks pes-ARKO-TRAMP and Wt-TRAMP prostate were double stained by $\mathrm{T}$-antigen (Red) and $\mathrm{N}$-cadherin (green). N-cadherin expression was increased in ARKO tumors (C) The increased -SMA, decreased AR and CK8 expressions were detected by Real-time PCR in ARKO tumors and lymph nodes (D) Illustrating the evolutional events in which the tumor cells keep transiting. 

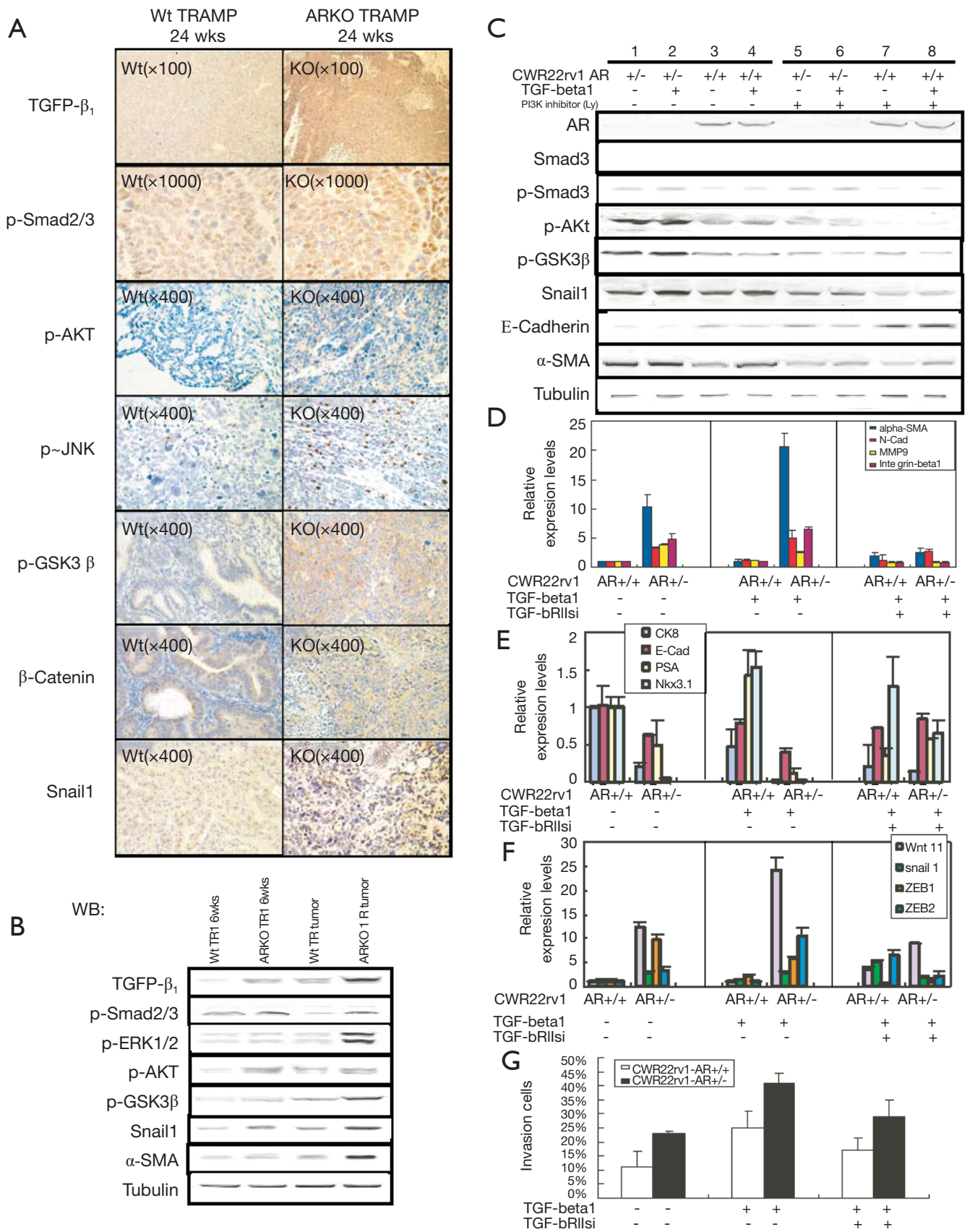

Figure 6 The mechanisms which may involve in the AR loss triggered EMT. (A) IHC staining of TGF-1, phospho-Smad2/3, phospho-AKT, phospho-JNK, phospho-GSK3 $\beta$, $\beta$-catenin and snai11 were carried out. (B) The expression of TGF- $\beta$, phospho-Smad2/3, phospho-ERK 1/2, phospho-AKT, phospho-GSK3 $\beta$, snaill and $\alpha$-SMA were confirmed in Western blot assay. (C) TGF- $\beta 1$ signaling through phosphor-AKT to activate snail1 and to result in EMT, which is characterized by decreased E-cadherin and increased $\alpha$-SMA expression, was blocked by Pl-3 $\mathrm{K}$ inhibitor LY2 94002 (Ly). (D) Using Real-time PCR to test the concept that the TGF- $\beta 1$ signaling is important for the EMT transition of CWR22rv1 cells. In the left panel, without any treatment, AR knockdown CWR22rv1- AR+/- cells expressed more mesenchymal markers, such as $\alpha$-SMA,N-cadherin, MMP9 and integrin $\beta 1$, than those of CWR22rv1-AR+/+ cells. $10 \mathrm{ng} / \mathrm{mL}$ TGF- $\beta 1$ treatment further induced the mesenchymal markers express in CWR22rv1-AR+/- cells (middle panel). Using TGF- $\beta 1$ receptor II siRNA (marked as TGF-bRllsi), the expression of these mesenchymal markers was significantly reduced in CWR22rv1-AR+/- cells (right panel) (E) The Real-time PCR results to show the TGF- $\beta 1$ signaling and blocking TGF- $\beta 1$ signaling significantly changed the expression of epithelial markers, such as CK8, E-cadherin, PSA, and Nkx3.1, in CWR22rv1-AR+/- cells (F) The Real-time PCR results to show the TGF- $\beta 1$ effects on the Wnt, snail, and ZEB signaling. (G) TGF- $\beta 1$ induced and TGF-bRllsi suppressed CWR22rv1-AR+/- cells invasion in CWR22rv1-AR+/- cells. 


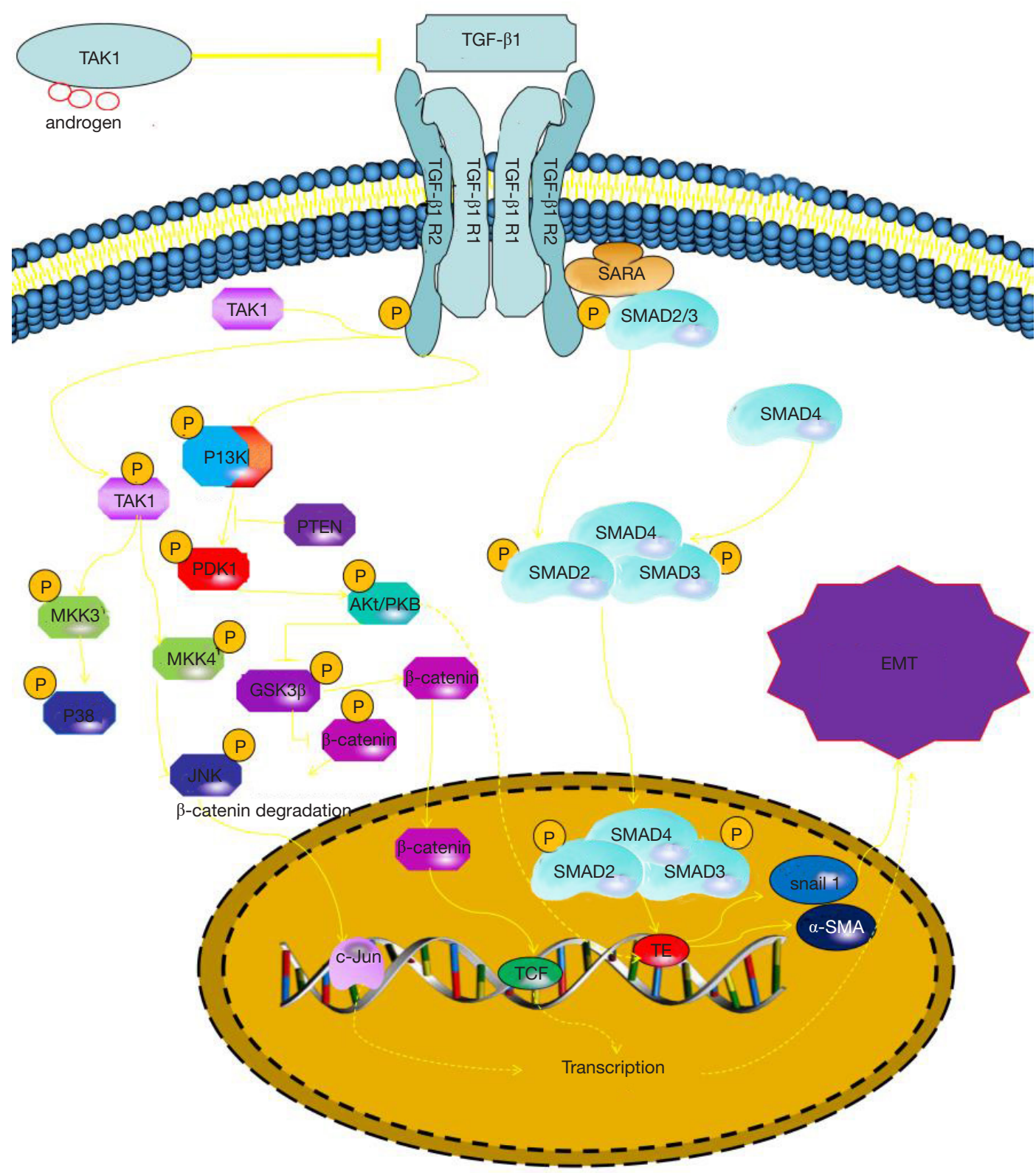

Figure 7 Androgen-binding AR inhibits TGF- $\beta$-related Pathway. Through binding signal molecules to TGF- $\beta$ receptors (TGF- $\beta$ R1 and TGF- $\beta$ R2), the receptors are phosphorylated to activate the SMAD signaling pathway and the non-SMAD signaling pathway. The SMAD signaling pathway begins with the co-SMAD gaining phosphorylation from TGF- $\beta$ receptor, and then binding to SMAD4 to form SMAD complex. The complex enters the nucleus and binds the transcription factor of Snail gene promoting the expression of Snail1. Because Snail1 is the key protein of EMT, it can induce the production of EMT. Non-SMAD pathways include TAK1 signaling and PI-3k signaling pathway, etc. The TAk1 signaling pathway starts with the phosphorylation of TAK1 factor, which leads to JNK phosphorylation acting on c-JUN to regulate the transcriptional activity of cells and promote cell proliferation and inhibit cells apoptosis. And PI-3K signaling pathway is caused by PI-3K factor binding phosphoric acid which leads to phosphorylation of AKT. Inhibition of GSk3ßand $\beta$-catenin Phosphorylation by phospho-AKt reduces the degradation of $\beta$-catenin, and then $\beta$-catenin converging in nucleus promotes cell proliferation and inhibits apoptosis by binding transcription factors. Furthermore, phospho-AKt factors can also lead to EMT by directly promoting the expression of EMT-related key proteins. 
properties (19). Significantly, the functional importance of decreased E-cadherin levels has also been demonstrated in PCa cells with its inverse correlation with cellular motility and protease expression $(20,21)$. Our results unexpected imply that AR signal deprivation may promote escape of TRAMP PCa cells in primary site and metastasis. This is according with a recent report revealing that EMT was easily induced by the condition of low intracellular AR levels (22).

Subsequently, we also found the diameter of pesARKO-TRAMP mice tumor or lymph node metastatic tumors were significantly larger than their WT TRAMP littermates. And orthotopic implantation of AR knockdown CWR22rv1-AR+/- cells developed larger xenograft tumors and bigger metastatic lymph nodes than those from parental CWR22rv1-AR+/+ cells. Mesenchymal-cell markers gain and epithelial-cell markers loss, particularly at the leading edge or invasive front of solid tumors, has been observed in human tumor specimens and is associated with tumor progression to metastasis (23). Our findings indicated that AR signal deprivation had effect on promoting the progression and metastasis of tumor, and support for our opinion.

Epithelial tumor cells lose many characters and meanwhile acquire protein mesenchymal-cell markers and signaling activities associated with mesenchymal cells facilitating migration and survival in an anchorageindependent environment and ultimately metastasis $(23,24)$. Interestingly, concomitant to the molecular alterations occurred on absence of E-cadherin and gain of Vimentin, $\mathrm{N}$-cadherin, and $\alpha$-SMA, we also found that AR signal deprivation is associated with cell morphology transition, high cell mobility, high cell invasion rate and resistance to anoikis in TRAMP prostate tumor cells. These data suggest that AR signal deprivation plays an important role on the changes of prostate epithelial cell morphology and promotes metastasis of tumor.

We present evidence for molecular mechanism that contributes to explain our finding, TGF $\beta 1$ signaling and Wnt signaling, as well as AKT and snails, are responsible for EMT change in AR knockout TRAMP tumor cells. TGF- $\beta$, a kind of multifunctional factor, regulates cellular responses in broad range (25). TGF- $\beta$ binds to type II and type I serine/threonine kinase receptors and transmits intracellular signals. Smads are the major transducer of TGF- $\beta$ signaling; Smad 2 and Smad3 are phosphorylated by the TGF- $\beta$ type I receptor and form complexes with Smad4. These complexes accumulate in the nucleus and regulate transcription of target genes (26). The mitogenactivated protein kinases' [MAPK; p38 MAPK, c-jun NH2terminal kinase (JNK), and extracellular signal-regulated kinase(ERK)-1/2] activation modulated Smad2/3 or other downstream transcription factors activity to increase TGF- $\beta$ signaling complexity (27-31) (including Snail1, Snail2, Notch, and others). The interference between TGF- $\beta$ signaling and androgen has been elaborated (32). A direct interaction between AR and TGF $\beta 1$ has been causally implicated in other human tumors (33). Androgens can inhibit TGF $\beta 1$-induced transcriptional activity in prostate cancer cells (34), an interaction that is regulated by AR-associated protein 55 (ARA55/Hic-5; LIM protein superfamily). Overexpression of ARA55 inhibits TGF $\beta 1$ h-mediated up-regulation of SMAD transcriptional activity in rat prostate epithelial cells, as well as human prostate cells, via an interaction between ARA5 5 and SMAD3 mediated through the MH2 domain of SMAD3 and the $\mathrm{C}$ terminus of ARA55 (35). Our results found the AR loss result in TGF- $\beta$, p-Smad2/3, p-AKT, p-JNK, p-GSK3 $\beta$, Snail1 proteins expression increased. In several cancer cells, E-cadherin expression can be repressed by Snail regulated by TGF- $\beta /$ Smad pathway (36-38). Our outcomes show that after knockdown AR, TGF- $\beta 1$ signaling through phosphorAKT to activate snaill and to result in EMT, which is characterized by increased $\alpha$-SMA expression and decreased E-cadherin, was blocked by PI-3 K inhibitor LY294002 (Ly). We also showed using TGF- $\beta 1$ receptor II siRNA (marked as TGF-bRIIsi), the expression of these mesenchymal markers ( $\alpha$-SMA, N-cadherin, MMP9 and integrin $\beta 1$ ) was significantly reduced in CWR22rv1-AR+/- cells. The TGF- $\beta 1$ signaling and blocking TGF- $\beta 1$ signaling significantly changed the expression of epithelial markers, such as CK8, E-cadherin, PSA, and Nkx3.1, in CWR22rv1$A R+/-$ cells. Our data also showed the TGF- $\beta 1$ effect on the Wnt and ZEB signaling. These results suggest that knockdown AR can independently induce EMT, potentially bypassing the effect elicited by TGF- $\beta$.

\section{Conclusions}

Taken together, our data reveal that PCa cell metastatic ability can be promoted by absence of AR by modulating EMT. This research put forward innovation view for the androgen-mediated EMT effect. ADT therapy induced hormone refractory prostate cancer may gain the ability of metastasis through cell's EMT which is a phase of poor differentiation. Anti-EMT drugs should be developed to 
battle the tumor metastasis induced by ADT therapy. The signaling pathways which involved in EMT progress need further elucidation.

\section{Acknowledgments}

Funding: This study was funded by China Postdoctoral Science Foundation Grant (No.2019M660060), Natural Science Foundation of Tianjin (No.19JCYBJC26900), The Science \& Technology Development Fund of Tianjin Education Commission for Higher Education (No.2018KJ050), Traditional Chinese medicine combined with Western medicine research project (2019137), Youth Fund of the Second Hospital Tianjin Medical University (No.2018ydey07), and Tianjin Technical Expert Project.

\section{Footnote}

Conflicts of Interest: All authors have completed the ICMJE uniform disclosure form (available at http://dx.doi. org/10.21037/tau.2020.03.02). The authors have no conflicts of interest to declare.

Ethical Statement: The authors are accountable for all aspects of the work in ensuring that questions related to the accuracy or integrity of any part of the work are appropriately investigated and resolved. The study was approved by research medical ethics committee of the Second Hospital of Tianjin Medical University (Grant No.KY2016K004).

Open Access Statement: This is an Open Access article distributed in accordance with the Creative Commons Attribution-NonCommercial-NoDerivs 4.0 International License (CC BY-NC-ND 4.0), which permits the noncommercial replication and distribution of the article with the strict proviso that no changes or edits are made and the original work is properly cited (including links to both the formal publication through the relevant DOI and the license). See: https://creativecommons.org/licenses/by-nc-nd/4.0/.

\section{References}

1. Siegel RL, Miller KD, Jemal A. Cancer statistics, 2020. CA Cancer J Clin 2020;70:7-30.

2. Wang X, Yin L, Rao P, et al. Targeted treatment of prostate cancer. J Cell Biochem 2007;102:571-9.

3. Chang CS, Kokontis J, Liao ST. Molecular cloning of human and rat complementary DNA encoding androgen receptors. Science 1988;240:324-6.

4. Quigley CA, De Bellis A, Marschke KB, et al. Androgen receptor defects: historical, clinical, and molecular perspectives. Endocr Rev 1995;16:271-321.

5. Yeh S, Tsai MY, Xu Q, et al. Generation and characterization of androgen receptor knockout (ARKO) mice: an in vivo model for the study of androgen functions in selective tissues. Proc Natl Acad Sci U S A 2002;99:13498-503.

6. Wilson JD, George FW, Renfree MB. The endocrine role in mammalian sexual differentiation. Recent Prog Horm Res 1995;50:349-64.

7. Cunha GR, Ricke W, Thomson A, et al. Hormonal, cellular, and molecular regulation of normal and neoplastic prostatic development. J Steroid Biochem Mol Biol 2004;92:221-36.

8. Cunha GR, Lung B. The possible influence of temporal factors in androgenic responsiveness of urogenital tissue recombinants from wild-type and androgen-insensitive (Tfm) mice. J Exp Zool 1978;205:181-93.

9. Suzuki H, Ueda T, Ichikawa T, et al. Androgen receptor involvement in the progression of prostate cancer. Endocr Relat Cancer 2003;10:209-16.

10. Bello D, Webber MM, Kleinman HK, et al. Androgen responsive adult human prostatic epithelial cell lines immortalized by human papillomavirus 18 . Carcinogenesis 1997;18:1215-23.

11. Danielpour D, Kadomatsu K, Anzano MA, et al.

Development and characterization of nontumorigenic and tumorigenic epithelial cell lines from rat dorsal-lateral prostate. Cancer Res 1994;54:3413-21.

12. Niu Y, Altuwaijri S, Yeh S, et al. Targeting the stromal androgen receptor in primary prostate tumors at earlier stages. Proc Natl Acad Sci U S A 2008;105:12188-93.

13. Niu Y, Altuwaijri S, Lai KP, et al. Androgen receptor is a tumor suppressor and proliferator in prostate cancer. Proc Natl Acad Sci U S A 2008;105:12182-7.

14. Thiery JP, Sleeman JP. Complex networks orchestrate epithelial-mesenchymal transitions. Nat Rev Mol Cell Biol 2006;7:131-42.

15. Berx G, Raspé E, Christofori G, et al. Pre-EMTing metastasis? Recapitulation of morphogenetic processes in cancer. Clin Exp Metastasis 2007;24:587-97.

16. Jennbacken K, Gustavsson H, Welén K, et al. Prostate cancer progression into androgen independency is associated with alterations in cell adhesion and invasivity. Prostate 2006;66:1631-40. 
17. Savagner P. Leaving the neighborhood: molecular mechanisms involved during epithelial-mesenchymal transition. Bioessays 2001;23:912-23.

18. Thiery JP. Epithelial-mesenchymal transitions in development and pathologies. Curr Opin Cell Biol 2003;15:740-6.

19. Cavallaro U, Schaffhauser B, Christofori G. Cadherins and the tumour progression: is it all in a switch? Cancer Lett 2002;176:123-8.

20. Kwok WK, Ling MT, Lee TW, et al. Up-regulation of TWIST in prostate cancer and its implication as a therapeutic target. Cancer Res 2005;65:5153-62.

21. Alexander NR, Tran NL, Rekapally H, et al. N-cadherin gene expression in prostate carcinoma is modulated by integrin-dependent nuclear translocation of Twist1. Cancer Res 2006;66:3365-9.

22. Zhu ML, Kyprianou N. Role of androgens and the androgen receptor in epithelial-mesenchymal transition and invasion of prostate cancer cells. FASEB J 2010;24:769-77.

23. Thiery JP. Epithelial-mesenchymal transitions in tumour progression. Nat Rev Cancer 2002;2:442-54.

24. Huber MA, Kraut N, Beug H. Molecular requirements for epithelial-mesenchymal transition during tumor progression. Curr Opin Cell Biol 2005;17:548-58.

25. Derynck R, Zhang YE. Smad-dependent and Smadindependent pathways in TGF-beta family signalling. Nature 2003;425:577-84.

26. Cardoso WV, Lü J. Regulation of early lung morphogenesis: questions, facts and controversies. Development 2006;133:1611-24.

27. Kamaraju AK, Roberts AB. Role of Rho/ROCK and p38 MAP kinase pathways in transforming growth factorbeta-mediated Smad-dependent growth inhibition of human breast carcinoma cells in vivo. J Biol Chem 2005;280:1024-36.

28. Hartsough MT, Mulder KM. Transforming growth factor beta activation of $\mathrm{p} 44 \mathrm{mapk}$ in proliferating cultures of epithelial cells. J Biol Chem 1995;270:7117-24.

29. Hanafusa H, Ninomiya-Tsuji J, Masuyama N, et al. Involvement of the $\mathrm{p} 38$ mitogen-activated protein kinase pathway in transforming growth factor-beta-induced gene expression. J Biol Chem 1999;274:27161-7.

30. Engel ME, McDonnell MA, Law BK, et al. Interdependent SMAD and JNK signaling in transforming growth factorbeta-mediated transcription. J Biol Chem 1999;274:3741320.

31. Willis BC, Borok Z. TGF- $\beta$-induced EMT: mechanisms and implications for fibrotic lung disease. Am J Physiol Lung Cell Mol Physiol 2007;293:L525-34.

32. Zhu ML, Kyprianou N. Androgen receptor and growth factor signaling cross-talk in prostate cancer cells. Endocr Relat Cancer 2008;15:841-9.

33. Yoon G, Kim JY, Choi YK, et al. Direct activation of TGF-beta 1 transcription by androgen and androgen receptor complex in Huh7 human hepatoma cells and its tumor in nude mice. J Cell Biochem 2006;97:393-411.

34. Chipuk JE, Cornelius SC, Pultz NJ, et al. The androgen receptor represses transforming growth factor-beta signaling through interaction with Smad3. J Biol Chem 2002;277:1240-8.

35. Wang H, Song K, Sponseller TL, et al. Novel function of androgen receptor-associated protein 55/Hic-5 as a negative regulator of Smad3 signaling. J Biol Chem 2005;280:5154-62.

36. Thuault S, Tan EJ, Peinado H, et al. HMGA2 and Smads co-regulate SNAIL1 expression during induction of epithelial-to-mesenchymal transition. J Biol Chem 2008;283:33437-46.

37. Nelson WJ, Nusse R. Convergence of Wnt, beta-catenin, and cadherin pathways. Science 2004;303:1483-7.

38. Barrallo-Gimeno A, Nieto MA. The Snail genes as inducers of cell movement and survival: implications in development and cancer. Development 2005;132:3151-61.

Cite this article as: Cai Q, Chen Y, Zhang D, Pan J, Xie Z, Ma S, Liu C, Zuo J, Zhou X, Quan C, Xin Z, Niu Y. Loss of epithelial AR increase castration resistant stem-like prostate cancer cells and promotes cancer metastasis via TGF- $\beta 1 /$ EMT pathway. Transl Androl Urol 2020;9(3):1013-1027. doi:10.21037/tau.2020.03.02 